\title{
EXPERIMENTAL INVESTIGATIONS OF OXYGEN STRIPPING FROM FEED WATER IN A SPRAY AND TRAY TYPE DE-AERATOR
}

\author{
K.V. Sharma ${ }^{1,4}$, K.V. Suryanarayana ${ }^{2}$, P.K. Sarma ${ }^{3}$, M.M.Rahman', M.M.Noor ${ }^{1}$, \\ and K. Kadirgama ${ }^{1}$ \\ ${ }^{1}$ Faculty of Mechanical Engineering, Universiti Malaysia Pahang, \\ 26600 Pekan, Kuantan, Pahang, Malaysia. \\ Email: kvsharma@ump.edu.my \\ ${ }^{2}$ Department of Chemical Engineering, Sri Venkateswara Engineering College, \\ Suryapet 508213, India. \\ ${ }^{3}$ International Director, GITAM University, Visakhapatnam 530045, India \\ ${ }^{4}$ Centre for Energy Studies, JNTUH College of Engineering, Hyderabad 500085, India
}

\begin{abstract}
The influence of various parameters on oxygen stripping for a two stage spray and tray type de-aerator is analyzed experimentally. It is observed that increasing the mass flow rate of water leads to an increase in heat and mass transfer coefficients in both stages. There is no significant influence of de-aerator pressure and length of the second stage on the heat transfer coefficients in the range tested. The increase in de-aerator pressure enhances the mass transfer coefficient by 14 percent, whereas the increase in length of the second stage has no significant influence. The empirical correlations available in the literature predict the mass transfer coefficients satisfactorily in the experimental range tested. The total length of the de-aerator is a significant parameter influencing the quantity of oxygen removed from the feed water.
\end{abstract}

Keywords: thermal de-aerator, spray and tray combination, condensation heat and mass transfer coefficients, oxygen stripped

\section{INTRODUCTION}

Boiler feed water may contain significant amounts of dissolved oxygen in the make-up water and/or due to seepage of air at the condenser. Corrosion due to pitting and iron deposition will be formed if the gas/air is not removed. Removal of the air takes place in a de-aerator, as even small quantities of dissolved gas can cause significant corrosion. The high temperature of the boiler feed water will enhance corrosion due to dissolved oxygen, if left untreated. In spray and and tray type de-aerators, the incoming water is passed through a hollow cone spray nozzle which is located at the top of the de-aerator. The liquid thus emerging from the nozzle forms a conical sheet at the nozzle outlet due to its tangential, radial and axial momentum forces. After traversing a small distance from the nozzle, the sheet breaks into ligaments and finally into droplets due to destabilizing forces. The droplets accumulate on a tray and flow as a jet through holes in it and finally collect at the bottom of the de-aerator. The water is then pumped to the boiler.

Experimental investigation of condensation of steam on a spray of water droplets was conducted by Brown (1951) in the diameter range of 0.125 to $0.520 \mathrm{~mm}$ and obtained heat transfer coefficients of the order of $27,000 \mathrm{~W} / \mathrm{m}^{2} \mathrm{~K}$. Ford and Lekic 
(1971) developed a correlation for the estimation of the growth of liquid droplets during condensation of steam in direct contact for three different diameters using high-speed photography. The experiment was conducted at various droplet temperatures below the saturation temperature of take into consideration unsteady state heat transfer. They modelled the droplet as a sphere with negligible heat transfer at the interface. Sundararajan and Ayyaswamy (1987) have carried out experimental studies on the effect of residence time on droplet size by introducing a non-dimensional condensation parameter, which considers the steam properties at far-stream along with the instantaneous surface temperature of the drop. They observed the value of the condensation parameter to decrease with an increase in time and droplet size. Experiments on direct contact condensation of steam with water sprays characterized by droplet size varying between 0.30 and $2.8 \mathrm{~mm}$, velocities between 0.85 to $9.0 \mathrm{~m} / \mathrm{s}$ and operating pressure up to $0.6 \mathrm{MPa}$ were undertaken by Celata et al. (1991). The experiments included the continuous measurement of the average droplet temperature along the axis of the spray. They obtained a condensation efficiency higher than that predicted by the pure conduction and internal circulation models. An empirical approach for the evaluation of the liquid mixing in the droplet has been undertaken by them and presented this efficiency as a function of the modified Peclet number. A comparison of the that model with the experimental data is found to be quite satisfactory.

Mayinger and Chavez (1992) conducted experiments on the growth of sub cooled spray droplets in a pure saturated vapour using the pulsed laser holography technique. The experimental values obtained by them predict high heat transfer coefficients in both sheet and droplet regions. Takahashi et al. (2001) studied the mechanism of condensation from a spray nozzle both theoretically and experimentally. They concluded from their analysis that the turbulence model predicted heat transfer in the first zone closer to the experimental data than did the pure conduction model. Nosoko et al. (2002) conducted experiments on oxygen absorption using a single column horizontal tube bank of $16 \mathrm{~mm}$ diameter and $284 \mathrm{~mm}$ wetted length. They found that the Sherwood number increases with an increase in tube spacing from 2 to $5 \mathrm{~mm}$ and then levels off at $10 \mathrm{~mm}$ or higher. They concluded that the volume of a horizontal tube absorber could be $1 / 2.2$ to $1 / 1.18$ times lower compared to vertical orientation for the same heat duty.

Experimental evaluations of condensation heat transfer coefficient from sprays by inducting non-condensable gas into the vapour region have been undertaken by many. However, in the literature, heat and mass transfer studies with a non-condensable gas such as oxygen getting stripped from the boiler feed water are quite limited in number. Hence, it is proposed here to study the influence of various operating parameters such as the flow rate of water, de-aerator length, de-aerator pressure, water temperature, oxygen concentration in the inlet water, etc., on the heat and mass transfer coefficients by conducting experiments with a spray and tray type de-aerator.

\section{EXPERIMENTAL SETUP}

The experimental setup consists of a column of $0.15 \mathrm{~m}$ dia. and $1.2 \mathrm{~m}$ length with a flexibility to enhance the total length to $2.1 \mathrm{~m}$ using spacers as shown in Figure 1. A nozzle located at the top of the de-aerator sprays water over a distance of $0.55 \mathrm{~m}$, referred to as the first stage. 


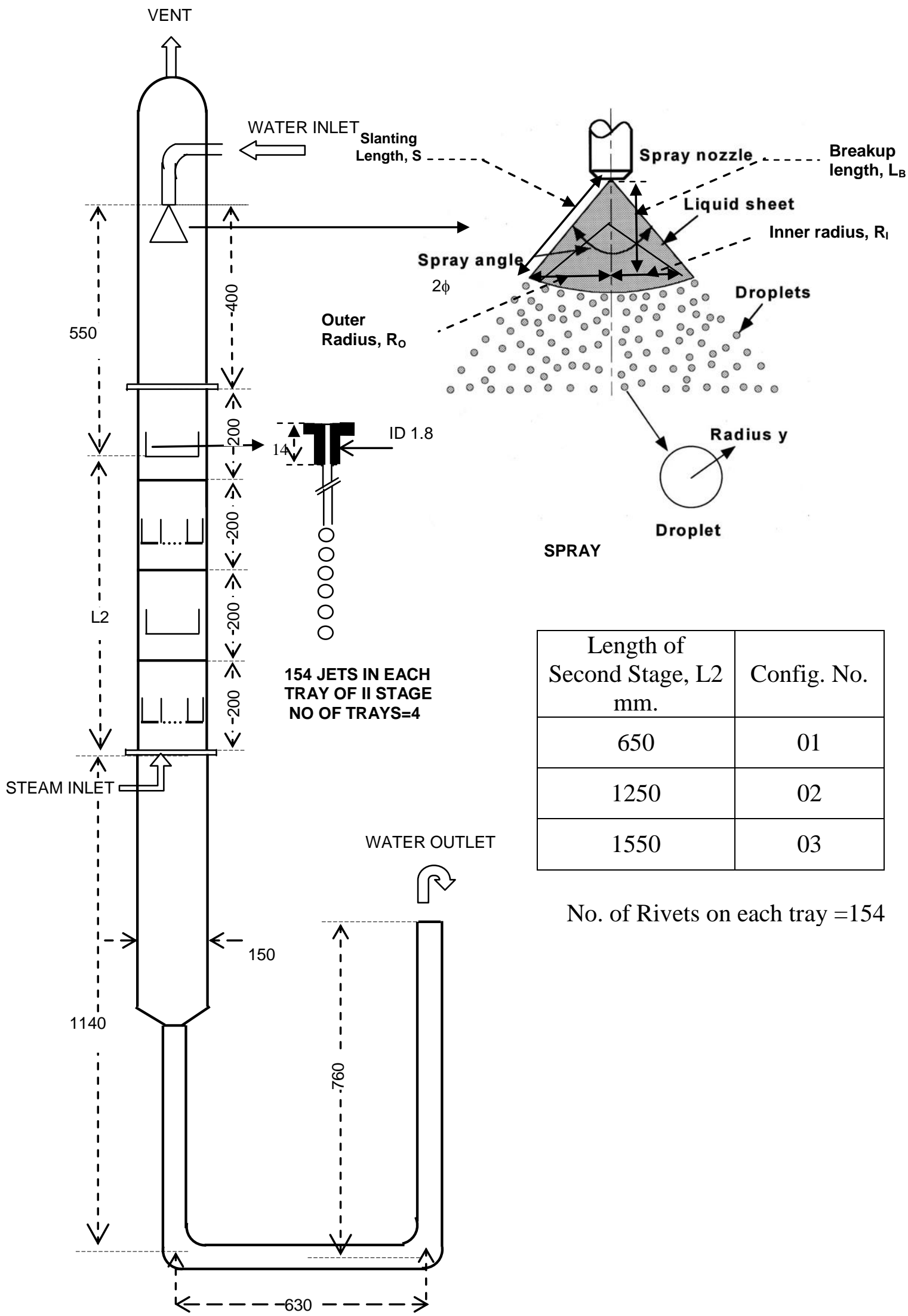

Figure 1: Schematic diagram of spray and tray type de-aerator 
A provision to adjust the spacing between trays with spacers of 200 and $300 \mathrm{~mm}$ length is available in the second stage of the de-aerator. The trays can be used either individually or in combination to vary the total height of the de-aerator. The water emanating from the nozzle gets accumulated on the first tray. The trays with holes as shown in Figure 1 allow water to flow from one to another as jets. The experiments were conducted at various flow rates, different de-aerator heights and pressures, inlet water temperatures, inlet concentrations and vent locations to evaluate the heat and mass transfer coefficients.

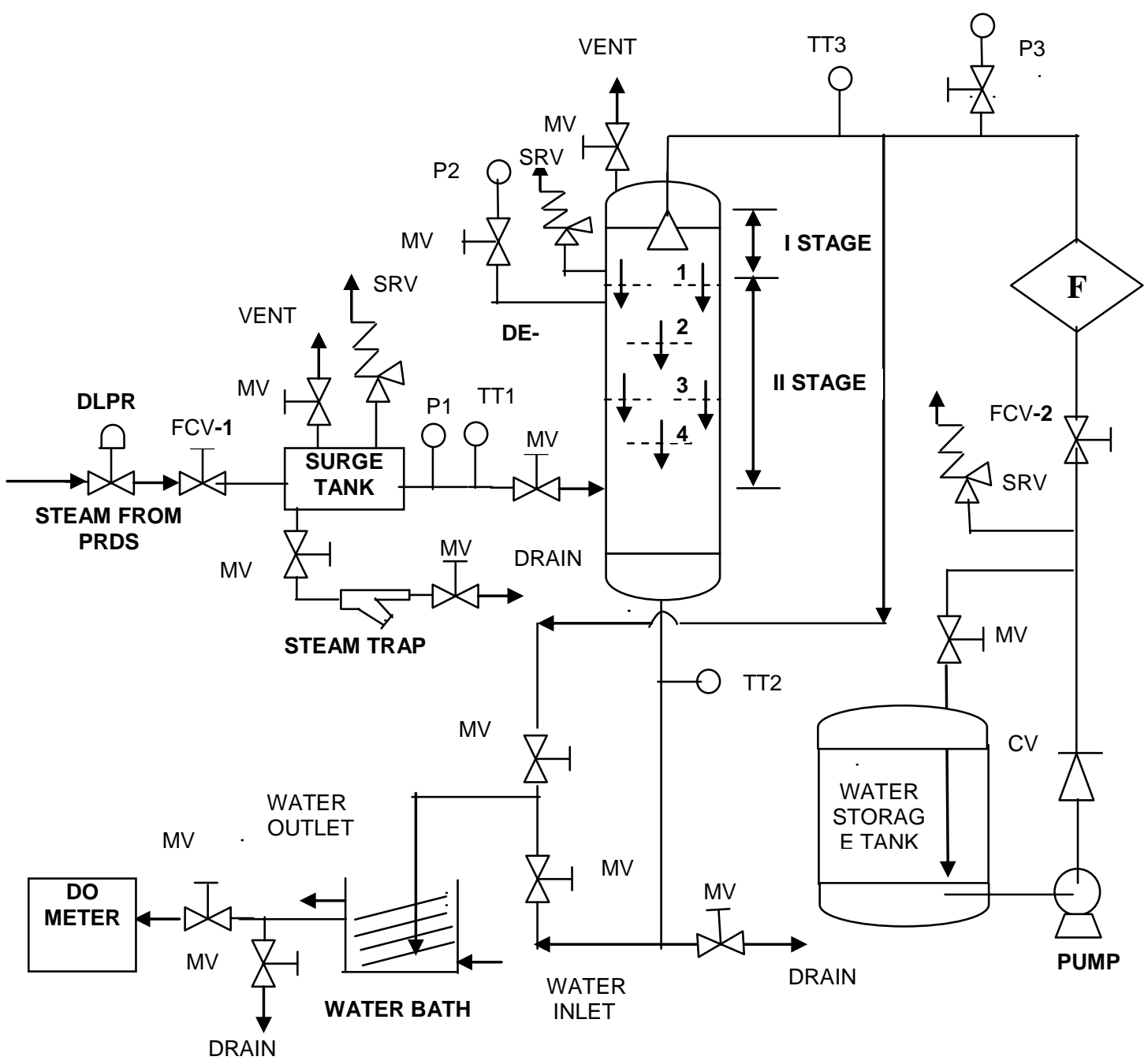

CV : Check Valve

DO : Dissolved Oxygen Meter

F : Flow Meter

P : Pressure Gauge

PRDS : Pressure Reducing \& Distribution System

SRV : Safety Relief Valve
DLPR : Dome Loaded Pressure Regulator

FCV : Flow Control Valve

MV : Manual Valve

TT : Temperature Transmitter

Figure 2: Process and instrumentation diagram of de-aerator experimental set-up 
A 200 liter feed water storage tank, a steam jacket on the de-aerator water inlet pipe for regulating its temperature, and a pump for circulating water are other accessories. In the steam circuit a pressure regulator and a steam trap are connected to a buffer tank for removal of water droplets after steam expansion in the pressure regulator. A water bath of 25 liters capacity with a copper coil to decrease the temperature of the sample water to vary between $30^{\circ} \mathrm{C}$ and $40^{\circ} \mathrm{C}$ is connected to a dissolved oxygen (DO) meter, and flow components such as valves, flow meters, pressure gauges and thermocouples are provided. The process and instrumentation diagram of the experimental setup is shown in Figure 2.

\section{ANALYSIS OF HEAT AND MASS TRANSFER COEFFICIENTS}

\section{Estimation of Heat Transfer Coefficient at Stage 1}

The determination of droplet size and hence the number of droplets can be predicted when the sheet $(s)$ or breakup length $\left(L_{B}\right)$ is known. The sheet length can be estimated using the empirical relation given by Eq. 1 (Lee and Tankin, 1984)

$$
\left[L_{B} /\left(A_{0}\right)^{1 / 2}\right]\left\lfloor 1+C_{1}\left(J a_{1}\right)^{C_{2}} e^{-C_{3}\left(W e_{1}-C_{4}\right)^{2}}\right\rfloor=C_{5} W e_{1}^{C_{6}}
$$

where $C_{1}=6.5, C_{2}=0.7, C_{3}=3 \times 10^{-6}, C_{4}=475$

and $W e_{1}<750, C_{5}=2.5$ and $C_{6}=0.30$

$$
W e_{1}>750, C_{5}=350 \text { and } C_{6}=-0.45
$$

The spray Weber number in this study varies between $790<W e<11250$ and corresponding mass flow rate between $0.033<m<0.125$. From the geometry of triangles, if the half cone angle $(\phi)$ of the nozzle and $L_{B}$ are known, the slanting length $(S)$ and outer radius $\left(R_{O}\right)$ of the sheet can be estimated. The sheet thickness $\left(\delta_{s}\right)$ at the location of breakup is estimated by Eq. 2 (Takahashi et al., 2001):

$$
\delta_{s}=m / 2 \pi R_{O} \rho_{L} V_{N}
$$

For the swirl cone angle of the nozzle $(2 \phi)$, the slanting length is calculated by Eq. 3 :

$$
S=L_{B} / \operatorname{Cos}(\phi)
$$

Using these values, the sheet volume can be estimated as in Eq. 4:

$$
v_{s}=\pi\left(R_{O}^{2}-R_{I}^{2}\right) \delta_{s} / 3
$$

The droplet diameter can be estimated according to the empirical relation of Dombowski and Munday (1967) for known conditions of de-aerator pressure, flow rate of water, which is expressed as Eq. 5:

$$
d_{1}=0.0134\left\lfloor F N^{0.209}\left(\mu_{L} / \rho_{L}\right)^{0.215}\right\rfloor /(-\Delta P)^{0.348}
$$


where $F N=2.08 \times 10^{6}(\mathrm{~m}) /\left[\rho_{L}\left(P_{D} / 1000\right)^{1 / 2}\right\rfloor$ and $\Delta P$ is the pressure drop across the nozzle. The number of droplets $(N)$ formed can be estimated as Eq. 6 :

$$
N=6 v_{s} / \pi d_{1}^{3}
$$

The surface area of $N$ droplets can be estimated with Eq. 7:

$$
A_{d}=N \pi d_{1}^{2}
$$

The heat transfer area is the sum of the areas of sheet and droplets:

$$
A_{1}=A_{s}+A_{d}
$$

The variation of droplet radius with time due to condensation can be estimated with the theoretical relation derived by Rao and Sarma (1985):

$$
r^{+}=r_{\text {con }}^{+} / E
$$

where $r_{\text {con }}^{+}=\left(J a_{1}+1\right)^{1 / 3} \quad ; E=\left[1+J a_{1} \exp \left(-\beta \tau^{+}\right)\right]^{1 / 3}$

The value of $\beta$ can be expressed as Eq. 10 .

$$
\beta=\frac{1}{\tau^{+}} \ln \left(\frac{1}{q}\right) \text { where } q=\frac{6}{\pi^{2}} \sum_{n=1}^{n=\infty} \frac{1}{n^{2}} \exp \left(-n^{2} \pi^{2} \tau^{+}\right)
$$

Thus Eq. 9 with the aid of Eq. 10 provides an explicit relation for the estimation of $r^{+}$. The condensate flow rate of the first stage is

$$
m_{C 1}=C_{P L}\left(T_{o}-T_{i}\right) m / H_{f g}
$$

The heat transfer coefficient due to condensation in the first stage and the temperature at the exit of first stage of de-aerator can be estimated with the help of Eq. (12) to Eq. (14).

$$
\begin{gathered}
h_{c o n}=H_{f g} m_{C 1} / A_{1}\left(T_{S}-T_{i 1}\right) \\
Q_{1}=h_{c o n} A_{1}\left(T_{S}-T_{i 1}\right) \\
T_{i 2}=T_{i 1}+\left(Q_{1} / m C_{P L}\right)
\end{gathered}
$$

The energy transferred to water in the de-aerator is the sum of the energies transferred in both stages:

$$
Q_{E}=Q_{1}+Q_{2}=m C_{P L}\left(T_{o}-T_{i 1}\right)
$$




\section{Estimation of Heat Transfer Coefficient at Stage 2}

A mathematical treatment of condensation on laminar and turbulent liquid jets taking into account the variation of flow rate over the jet cross section has been presented by Mochalova et al. (1988). They compared their analysis with the experimental data of Mills et al. (1982) and presented an explicit solution for the estimation of heat transfer coefficient in terms of the Reynolds, Prandtl, and Weber numbers in addition to other geometric parameters governing the flow.

For laminar flow, the explicit equation for the Stanton number is given by Mochalova et al. (1988) as Eq. (16a):

$$
S t=\left(f_{1} f_{2} f_{3}-0.004 J a_{2}\right)\left(L_{2} / D_{J}\right)^{-0.8} \text { for } \operatorname{Re}_{H} \leq 1500
$$

For turbulent flow,

$$
\begin{aligned}
& S t=B\left(0.047-0.035 \mathrm{Ja}_{2}\right)\left(L_{2} / D_{J}\right)^{-0.52} \operatorname{Re}_{H}{ }^{-0.033} \operatorname{Pr}^{-0.1} \mathrm{Fr}^{-0.064} ; 0.001<J a_{2}<1 ; \\
& 1500<\operatorname{Re}_{H}<20,000 ; 1<\operatorname{Pr}<50 ; 50<F r<15,000
\end{aligned}
$$

where

$B=1 \quad$ if the initial velocity profile is plane

$B=0.18\left(L_{2} / D_{J}\right)^{0.26}$ if the initial profile is parabolic

$$
\begin{aligned}
& f_{1}=1.25 \times 10^{-2}-7.5 \times 10^{-6} \operatorname{Re}_{H} ; \quad f_{2}=1.05-\operatorname{Pr}\left[8 \times 10^{-3}-3 \times 10^{-4}\left(L_{2} / D_{J}\right)\right] \text {; } \\
& f_{3}=1.05-C^{3 / 4} \operatorname{Re}_{H}^{-2} W e_{2}+\left(L_{2} / D_{J}\right)\left(0.03-0.6 C^{3 / 4} \operatorname{Re}_{H}^{-2} W e_{2}\right) \text { for } W e_{2}<2.5 \text {; } \\
& f_{3}=1.05-C^{3 / 4} \operatorname{Re}_{H}^{-2} W e_{2}\left[0.4+0.01\left(L_{2} / D_{J}\right)\right] \quad \text { for } W e_{2} \geq 2.5 \text {; } \\
& C=g D_{J}^{3} / 8 v_{2}^{2} ; \quad \operatorname{Re}_{H}=V_{2} D_{J} / 2 v_{2} ; \quad \operatorname{Pr}=v_{2} / \alpha_{2} ; \\
& W e_{2}=\rho_{L} V_{2}^{2} D_{J} / 2 \sigma_{2} ; \quad F r=2 V_{2}^{2} / g D_{J} ; \quad h_{2 T}=S t \rho_{L} V_{2} C_{P L 2}
\end{aligned}
$$

The heat transfer coefficient $h_{2 T}$ for liquid jets in the second stage can be validated with the overall energy balance equation, if the surface area for heat transfer can be determined. The surface area for heat transfer depends on the phenomenon of liquid jet breakup. The hydraulic break up length of the jet emerging from $1.8 \mathrm{~mm}$ diameter holes of the tray is estimated by Eq. 17 according to the empirical correlation of Celata et al. (1989),

$$
L_{h b} / D_{J}=29+1.9\left(W e_{2}\right)^{1 / 2} .
$$

The volume of water in the jet up to the break-up length can be estimated as:

$$
v_{J}=\pi D_{J}^{2} L_{h b} / 4
$$

Spherical droplet formation takes place on the breakup of the liquid jet. The diameter and volume of the droplet formed on breakup can be estimated as (Hinze, 1955): 


$$
d_{2}=1.89 D_{J} ; v_{d 2}=\pi d_{2}^{3} / 6
$$

The number of droplets $N$ formed from each jet in the second stage can be estimated as:

$$
N=v_{J} / v_{d 2}
$$

The surface area of 154 liquid jets emanating from each tray is the sum of the areas up to the breakup length and that of the droplets formed thereafter

$$
A_{t}=154 \pi\left(D_{J} L_{h b}+N d_{2}^{2}\right)
$$

As the height of the jet between the third and bottom tray is only $0.05 \mathrm{~m}$ and less than the breakup length, the surface area exposed to steam is taken for consideration. Hence, the total heat transfer area of the second stage considering all the trays is

$$
A_{2}=3 A_{t}+154\left(0.05 \pi D_{J}\right)
$$

The heat transferred in the second stage of the de-aerator can be estimated from the difference relation

$$
Q_{2}=Q_{E}-Q_{1}
$$

The overall heat transfer coefficient of the second stage can be estimated according to Newton's law

$$
h_{2 E}=Q_{2} / A_{2}\left(T_{S}-T_{i 2}\right)
$$

The total heat transferred can be estimated as:

$$
Q_{T}=h_{\text {con }} A_{1}\left(T_{S}-T_{i 1}\right)+h_{2 T} A_{2}\left(T_{S}-T_{i 2}\right)
$$

The values obtained from Eq. (25) are validated with the energy balance, Eq. (15).

A regression equation for the estimation of the overall heat transfer coefficient has been developed with 85 experimental values and with an average deviation of $3 \%$ and standard deviation of $4 \%$ as

$$
U_{\operatorname{Re} g}=1.123\left(m C_{P L} / A\right)^{0.888}\left(T_{S} / T_{i 1}\right)^{0.1839}\left(L / D_{N}\right)^{0.09354}
$$

valid for the operating conditions $0.033<m<0.125 \mathrm{~kg} / \mathrm{s}, 350<L / D_{N}<600$ and $1.1<T_{S} / T_{i 1}<1.4$. 


\section{Estimation of the Mass Transfer Coefficient at Stage 1}

The objective of the present analysis is to estimate the quantity of oxygen diffusing from the solvent water. This is formulated as one related to the diffusion of oxygen from the droplet centre to its surface. In this formulation, the assumptions are as follows:

1. The configuration of the droplet is a perfect sphere.

2. Diffusion occurs under non-isothermal conditions, i.e., the major resistance for diffusion is within the droplet and the resistance decreases as the temperature of droplet increases.

3. The resistance for diffusion of gas from the interface to steam is negligible.

The component continuity equation can be written as follows:

$$
(\pi / 6) d^{3} \rho_{L}[d X(t) / d t]=-k_{L, d} C_{A} \pi d^{2}
$$

The oxygen concentration $\left(C_{A}\right)$ in the inlet water can be expressed as Eq. (28) in terms of the bulk density of water and the mass fraction of oxygen dissolved in it.

$$
C_{A}=\rho_{L} X
$$

For flow past a single sphere, the mass transfer coefficient under forced and free convective conditions, according the to well established dimensionless equation of Steinberger and Treybal (1960), is

$$
S h_{d}=S h_{0}+0.347\left(\operatorname{Re}_{d} S c_{d}{ }^{0.5}\right)^{0.62}
$$

valid in the range $0.6<S c_{d}<4000$ and $1.8<\operatorname{Re}_{d}<6 \times 10^{5}$

The initial Sherwood number $S h_{0}$ can be evaluated as follows:

$$
\begin{aligned}
& S h_{0}=2+0.569\left(G r_{d} S c_{d}\right)^{0.25} \text { for } G r_{d} S c_{d}<10^{8} \\
& S h_{0}=2+0.0254\left(G r_{d} S c_{d}\right)^{0.333} S c_{d}^{0.244} \text { for } G r_{d} S c_{d}>10^{8}
\end{aligned}
$$

Eq. 27 can be rewritten with the aid of Eq. 28 and Eq. 29 as

$$
d X(t) / d t=-6\left(S h_{d} D_{L} X(t)\right) / d^{2}
$$

where $D_{L}=\left(7.481 \times 10^{-16}\left(T_{A V}\right)\right) /\left(\mu_{L} v_{A}{ }^{0.6}\right)$ with the initial condition at $t=0, X=X_{i}$.

Integration of Eq. 31 yields

$$
X(t) / X_{i}=\exp \left\{-6\left[\left(S h_{d} D_{L} t\right) / d^{2}\right]\right\}
$$




\section{Estimation of the Mass Transfer Coefficient at Stage 2}

The following assumptions are made in the analysis to evaluate the quantity of dissolved oxygen removed when the liquid emanates as a jet:

1. The jet is cylindrical in configuration.

2. The diffusion process occurs under non-isothermal conditions of jet, i.e., the major resistance for diffusion is within the liquid jet and the resistance decreases as jet temperature increases.

3. The resistance for the diffusion of oxygen from the interface of the jet to the steam environment is negligible.

From the component continuity equation we obtain

$$
(\pi / 4) D_{J}^{2} L_{h b} \rho_{L}[d X(t) / d t]=-k_{L, J} C_{A} \pi D_{J} L_{h b}
$$

The empirical correlations for falling films in the laminar- wavy-, transition- and turbulent flow regime are listed as follows (Mayinger, 1982):

$$
\begin{aligned}
& S h_{J}=2.24 \times 10^{-2} \operatorname{Re}_{J}^{0.8} S c_{J}^{0.5} \text { for } 12 \leq \operatorname{Re}_{J} \leq 70 \text { and } S c_{J} \geq 2.32 \times 10^{4} / \operatorname{Re}_{J}^{1.6} \\
& S h_{J}=8.0 \times 10^{-2} \operatorname{Re}_{J}^{0.5} S c_{J}^{0.5} \text { for } 70 \leq \operatorname{Re}_{J} \leq 400 \text { and } S c_{J} \geq 1.82 \times 10^{3} / \operatorname{Re}_{J} \\
& S h_{J}=8.9 \times 10^{-4} \operatorname{Re}_{J}^{1.25} S c_{J}^{0.5} \text { for } \operatorname{Re}_{J} \geq 400 \text { and } S c_{J} \geq 1.47 \times 10^{7} / \operatorname{Re}_{J}^{2.5}
\end{aligned}
$$

Eq. 33 can be arranged and solved in conjunction with Eq. 34 for the initial condition $t=0, X=X_{i}$ to give

$$
X(t) / X_{i}=\exp \left\{-4\left(S h_{J} D_{L} t / \delta D_{J}\right)\right\}
$$

Eqs. 32 and 35 have been solved for different values of inlet mass flow rates, deaerator lengths and inlet oxygen concentration in the experimental range and the results are presented here. A regression equation has been developed, Eq. 36, for the estimation of the Sherwood number in the experimental range of $0.033<m<0.125 \mathrm{~kg} / \mathrm{s}$, $350<L / D_{N}<600$ and $1.1<T_{S} / T_{i 1}<1.4$ :

$$
S h_{\operatorname{Re} g}=0.4044\left(\operatorname{Re}_{N i}\right)^{0.4859}\left(S c_{N i}\right)^{0.5674}\left(L / D_{N}\right)^{-0.4895}\left(T_{S} / T_{i 1}\right)^{0.0514}
$$

with an average deviation of $2.54 \%$ and standard deviation of $3.84 \%$.

\section{RESULTS AND DISCUSSION}

The temperature and concentration at the end of the first stage are evaluated using Eqs. 14 and 32, respectively, and the salient results presented. Figure 3 shows the effect of mass flow rate of de-aerator water on condensation heat transfer coefficient. It can be observed that an increase in the mass flow rate of the de-aerator water increases the heat transfer coefficients in the first and second stages. The rate of increases are more in the first stage than in the second due to the higher temperature potential between the steam 
and water. An increase in the de-aerator pressure and length of the second stage has a negligible effect on the heat transfer coefficient. An increase in the non dimensional droplet radius estimated with Eqs. 9 and 10 of Rao and Sarma (1985) at the exit of the first stage, and that calculated with data from experiments using energy balance Eq. 11, are shown plotted in Figure 4. The close agreement between the two estimates, varying by less than $2 \%$, ensures the reliability of the present data. Figure 5 shows a comparison of the experimental heat transfer coefficients evaluated with the energy balance equation with those estimated with the theoretical analysis of Mochalova et al. (1988) for the second stage. A good agreement of estimated values with experimental study is observed.

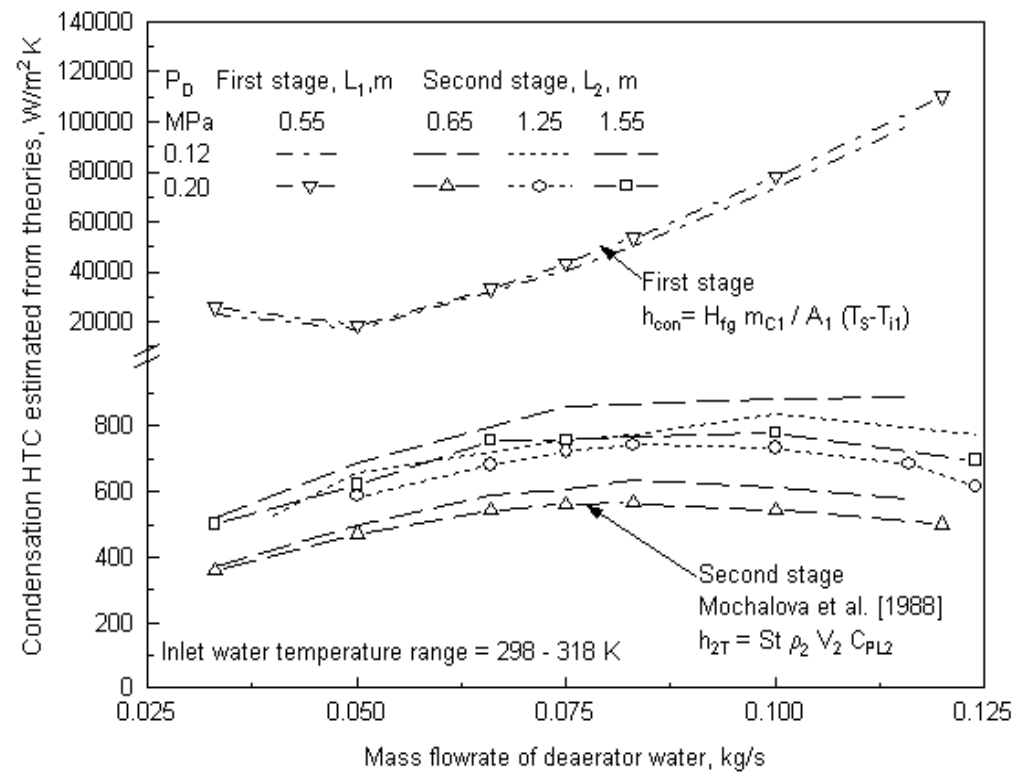

Figure 3: Effect of mass flow rate of de-aerator water on condensation heat transfer coefficient estimated from theories of different authors

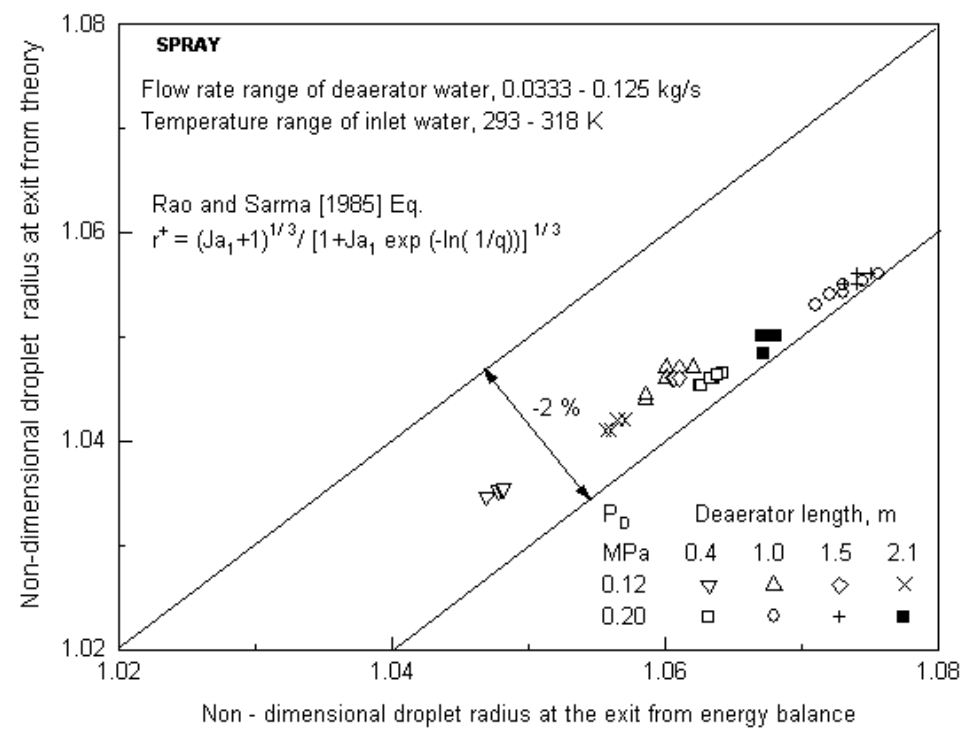

Figure 4: Comparison of first stage dimensionless droplet radius $r+$ estimated with Eq. 10 at the exit with experimental data 


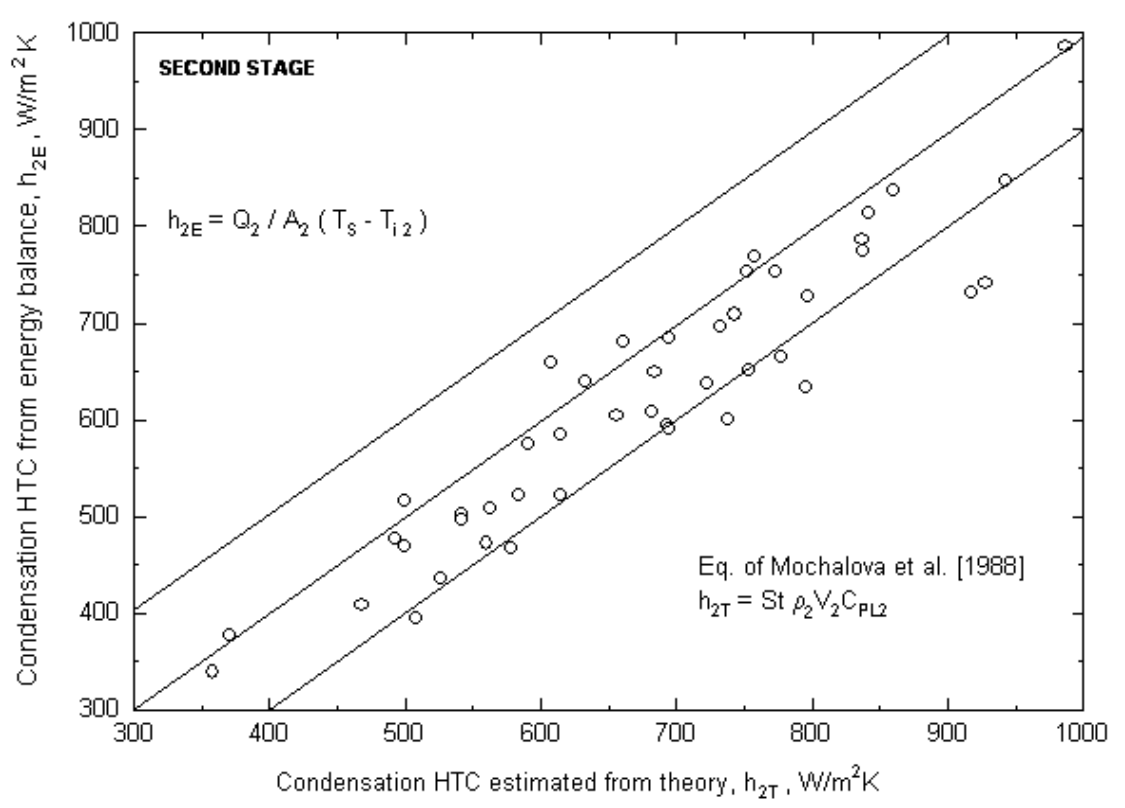

Figure 5: Comparison of experimental values of condensation heat transfer coefficients with values estimated using Eq. 12

A comparison of the heat transferred from both stages estimated from the energy balance Eq. 15 with the values estimated using Eq. 25 shows good agreement as can be seen from Figure 6. This validates the heat transfer coefficients estimated with Eqs. 12 and 16 for the first and second stages, respectively. The overall condensation heat transfer coefficient of two stage spray and tray type de-aerator is found to vary between 400 and $1600 \mathrm{~W} /\left(\mathrm{m}^{2} \mathrm{~K}\right)$. Values estimated from the regression Eq. 26 are shown in Figure 7, which is in good agreement with the values evaluated with the energy balance equation, $U_{E}=Q_{E} / A\left(T_{S}-T_{i 1}\right)$.

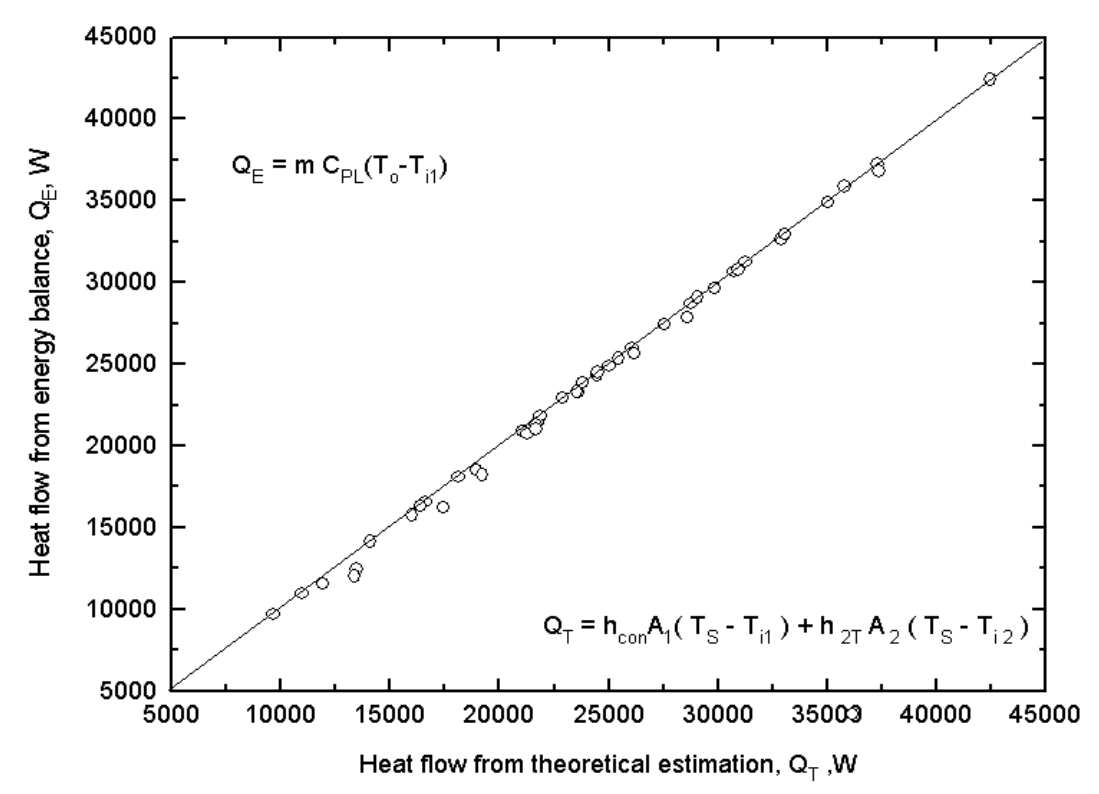

Figure 6: Comparison of total heat transfer estimated from theory with values from experiments 


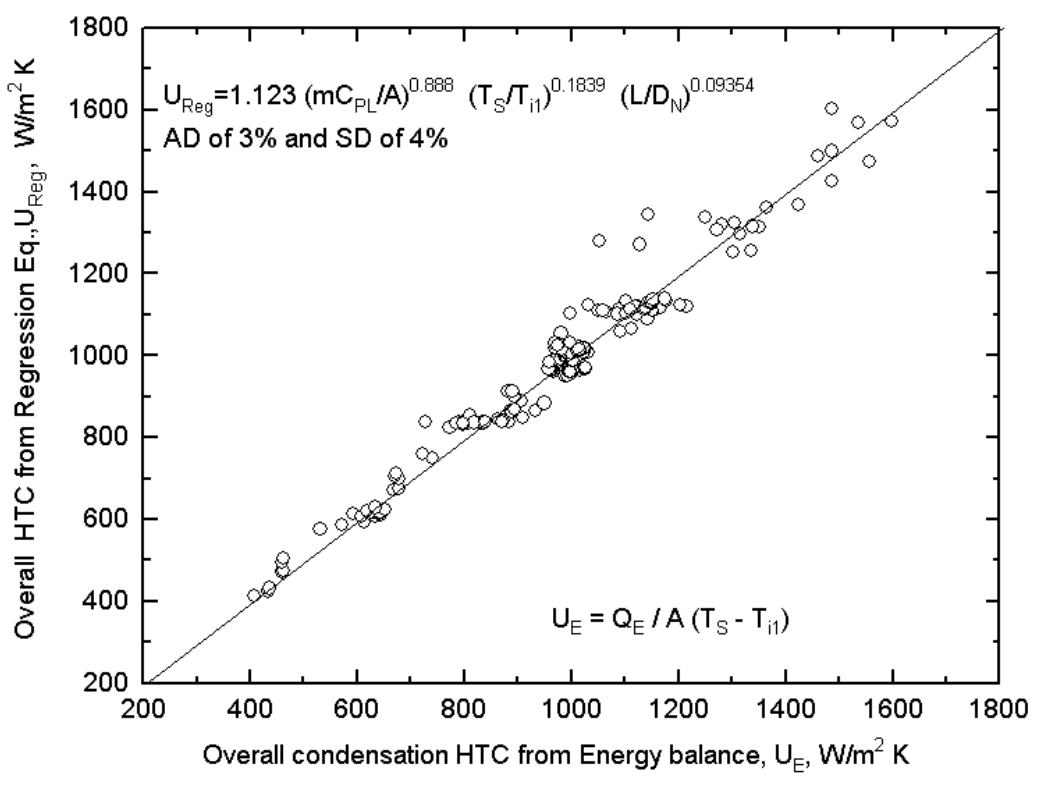

Figure 7: Comparison of the overall condensation heat transfer coefficients estimated using the regression equation with the experimental data

The increasing trends of mass transfer coefficients shown in Figures 8 and 9 for the first and second stages of the de-aerator with an increase in the mass flow rate of water is similar to the increases in the heat transfer coefficient as can be seen from a comparison with Figure 3. The rate of increase is more in the first stage than in the second due to the higher concentration potential between steam and water. The increase in de-aerator pressure from 0.12 to $0.2 \mathrm{MPa}$ enhances the mass transfer coefficient in the second stage. This may be attributed to the squeezing of oxygen from the water at higher pressure. The increase in length of the second stage has a negligible effect on the mass transfer coefficient.

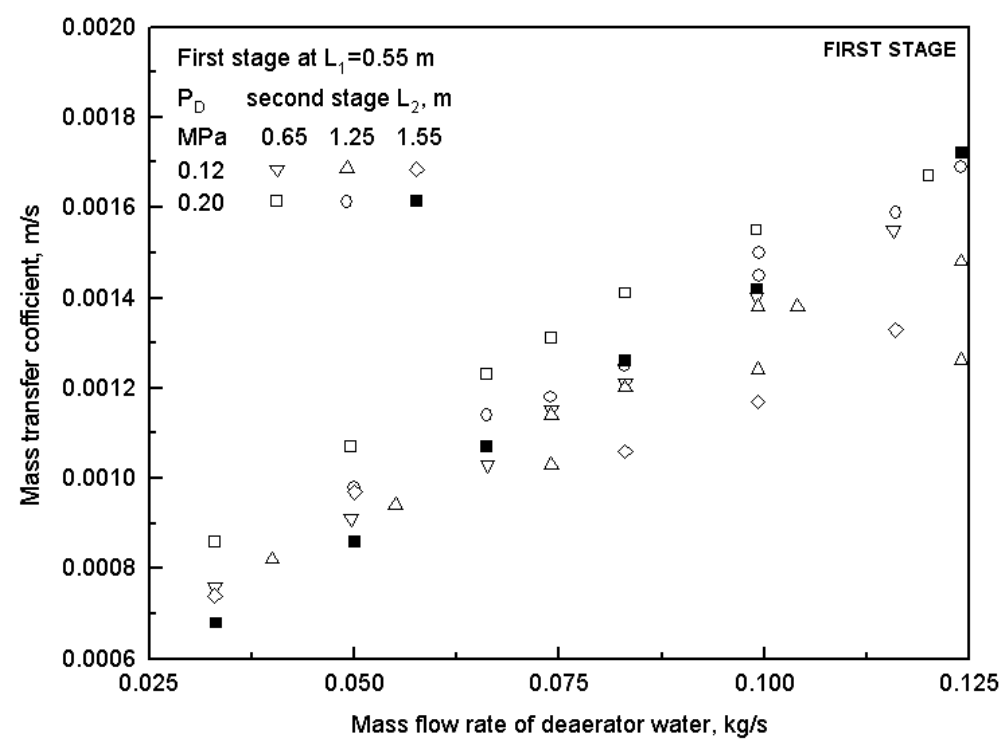

Figure 8: Effect of mass flow rate of de-aerator water on mass transfer coefficient under different operating conditions of the first stage 
The variation of the Reynolds number with $\left(S h_{J 2} \times S c_{J 2}^{-0.5}\right)$ for different operating conditions in the second stage of spray and tray type de-aerator is shown in Figure 10. The experimental values are in good agreement with the values estimated with the equation of Bakopoulos (1980) for the second stage. However the author has not presented information as to the quantity of oxygen removed. The values of the Sherwood number estimated with the regression equation is in good agreement with the experimental values as shown in Figure 11 demonstrating the validity of the proposed Eq. 36. The effect of de-aerator length on the variation of oxygen concentration in inlet water is shown in Figure 12. The oxygen concentration decreases rapidly initially in a length of $0.4 \mathrm{~m}$ and remains constant thereafter.

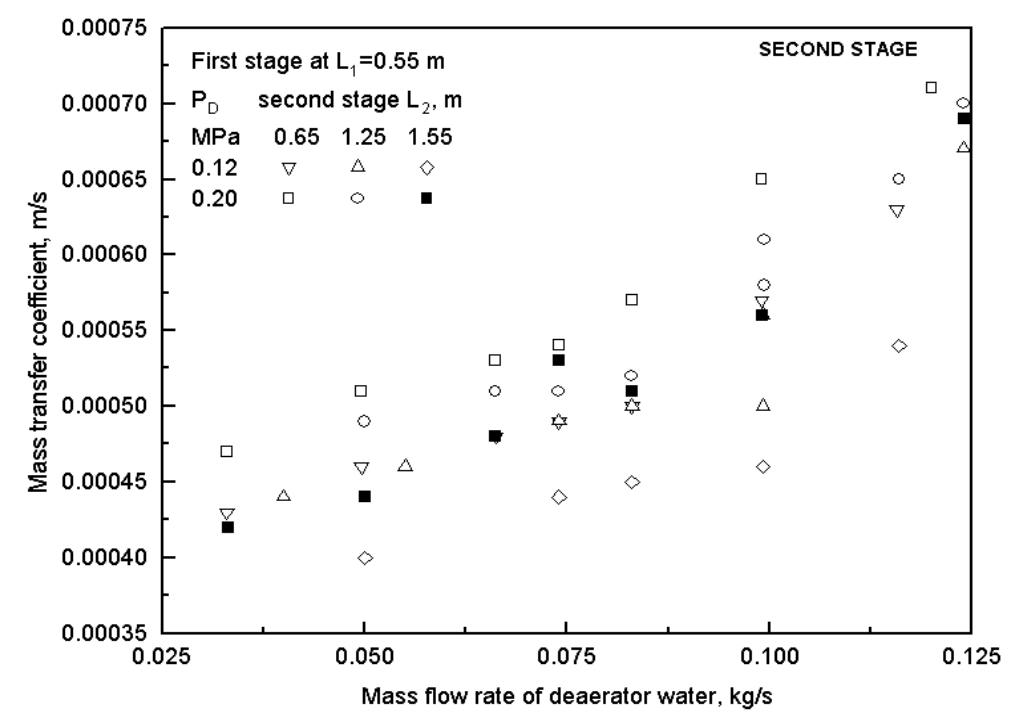

Figure 9: Effect of mass flow rate of de-aerator water on mass transfer coefficient under different operating conditions of the second stage

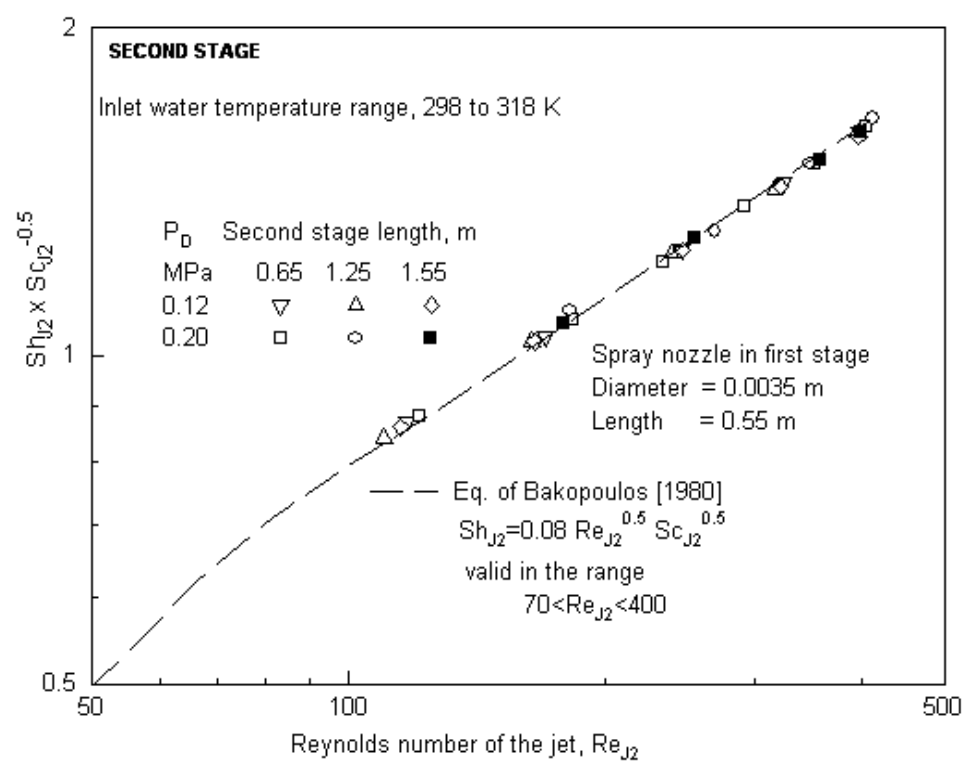

Figure 10: Effect of Reynolds number on Sherwood-Schmidt product under different operating conditions of the second stage 


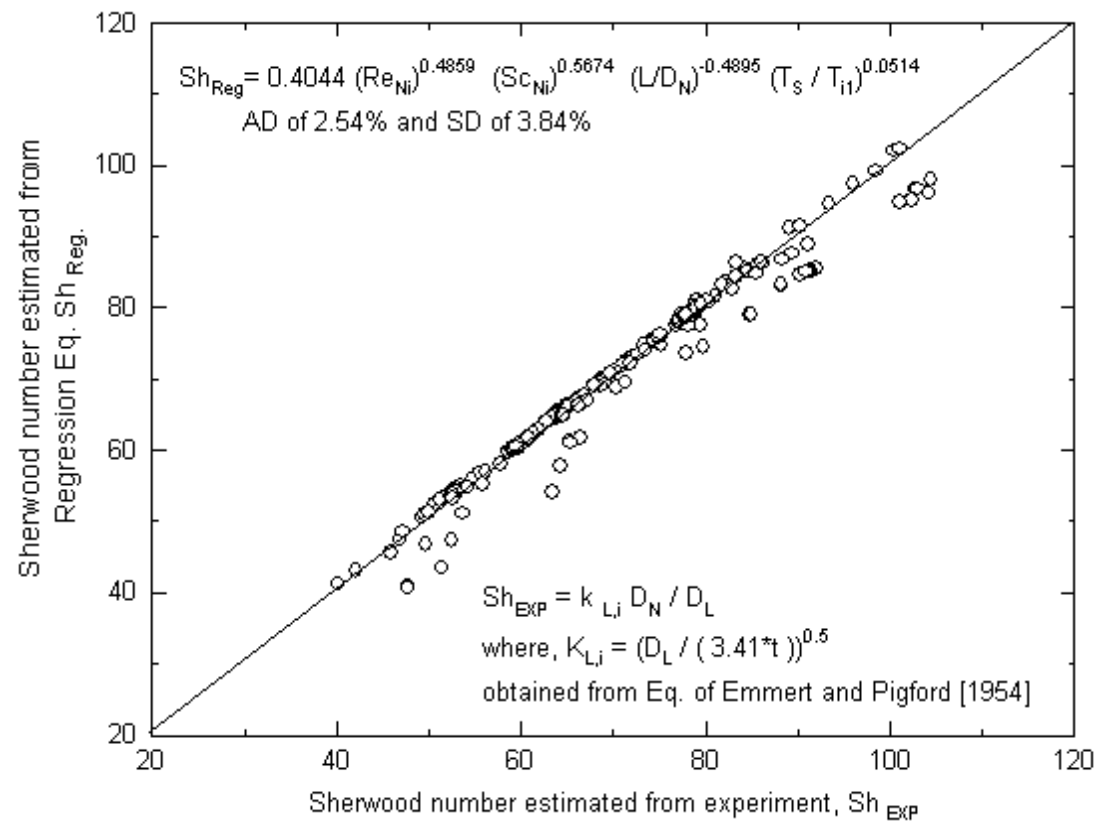

Figure 11: Comparison of Sherwood number from regression equation with experimental values

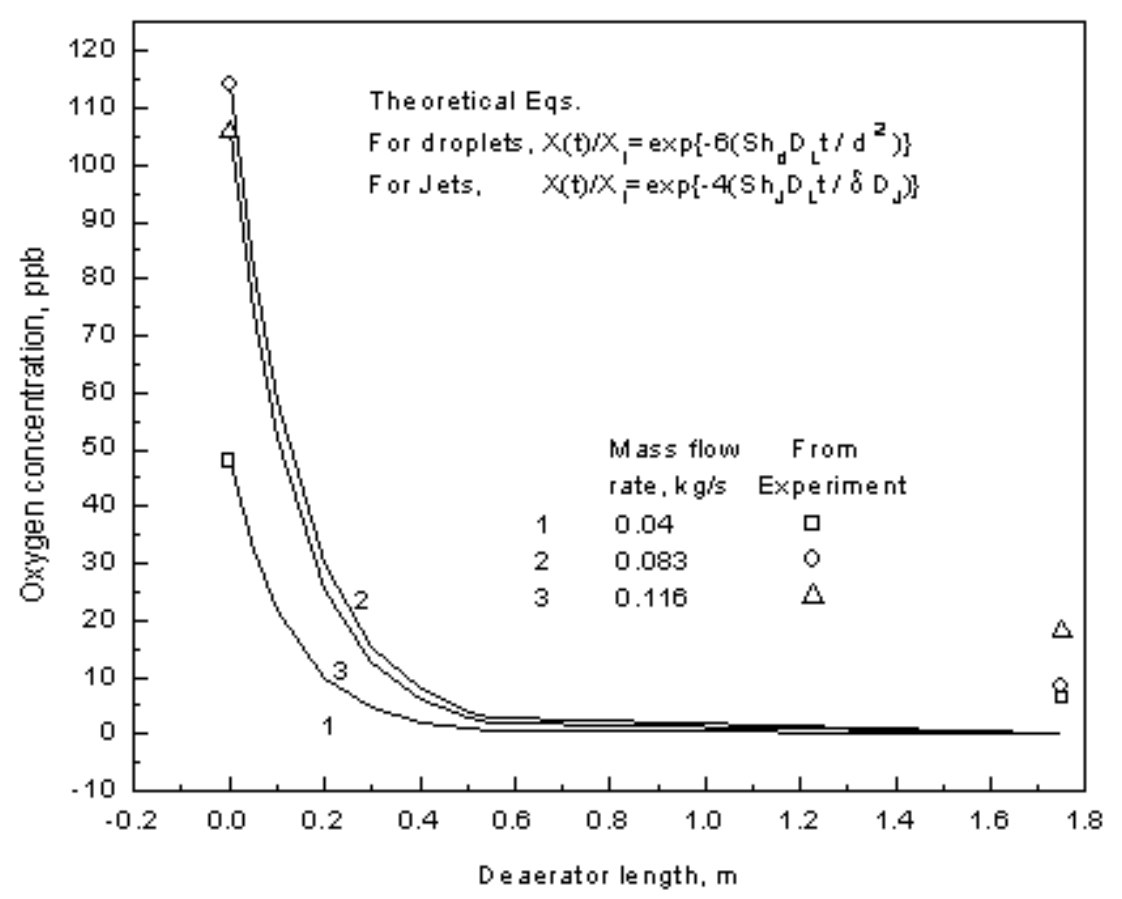

Figure 12: Effect of de-aerator length on oxygen concentration in feed water from theory and comparison with experiment data

Figure 13 shows a comparison of the values of oxygen removed due to stripping with that calculated with theory using Eqs. 32 and 35 for the first and second stages, respectively. It can be observed that the values obtained from experiments are higher than the values predicted from theory. This may be due to re-absorption of oxygen at the end of the second stage for the flow rates conducted. Hence, the possibility of re- 
absorption of oxygen cannot be prevented, if the height of the second stage and liquid flow rates are not maintained at the design conditions. The re-entry of oxygen can be avoided if a separate second stage is provided.

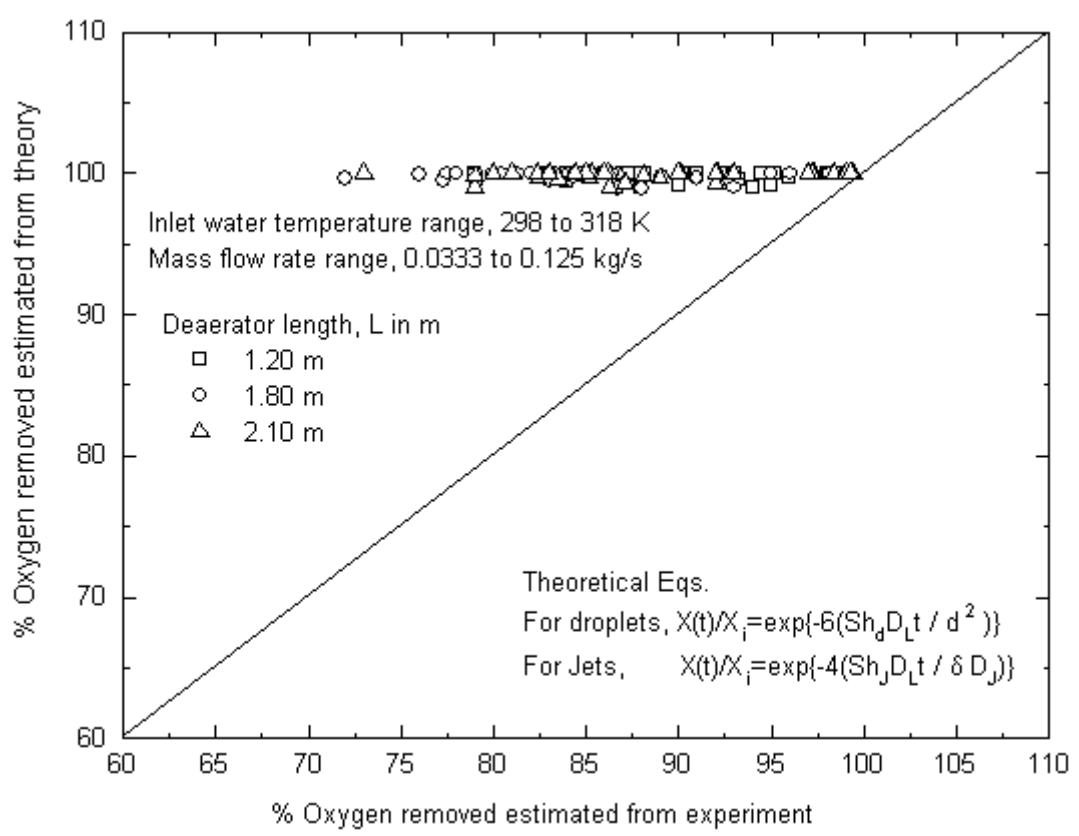

Figure 13: Percentage of oxygen removed - comparison of experimental values with theory

\section{CONCLUSIONS}

The following conclusions can be drawn from the analysis of spray and tray type deaerators:

a) The influence of the mass flow rate of water on the heat and mass transfer coefficients of both stages of the de-aerator are significant.

b) There is no significant influence of de-aerator pressure on the heat transfer coefficients in both stages of the de-aerator

c) An increase in length of the second stage has no significant effect on the heat and mass transfer coefficients.

d) Increases in de-aerator pressure from 0.12 to $0.2 \mathrm{MPa}$ enhance the mass transfer coefficient in the second stage by $12 \%$.

e) The oxygen removal rate from the feed water is large initially due to large concentration difference and decreases slowly thereafter.

f) Mayinger's empirical correlations can be used to estimate the Sherwood numbers of the first and second stages.

g) Regression Eqs. 26 and 36 can be used for the estimation of heat and mass transfer coefficients useful in the design of the de-aerator.

h) The predicted values of oxygen concentration are higher than the experimental values. 


\section{ACKNOWLEDGEMENTS}

The financial support by the Universiti Malaysia Pahang and Sri V. Satyender, Secretary of Sri Venkateswara Engineering College, Suryapet, India are gratefully acknowledged.

\section{REFERENCES}

Bakopoulos, A. (1980) Liquid side controlled mass transfer in wetted-wall tube. German Chemical Engineering, 3: 241-252.

Brown, G. (1951) Heat transmission by condensation of steam on a spray of water drops. Proceedings of General Discussion on Heat Transfer, Institute of Mechanical Engineering ,pp. 49-52.

Celata, G.P., Cumo, M., D’Annibale, F. and Farello, G.E. (1991) Direct contact condensation of steam on droplets. International Journal of Multiphase Flow, 17(1): 191-211.

Celata, G.P., Cumo, M., Farello, G.E. and Focardi, G. (1989) A Comprehensive analysis of direct contact condensation of saturated steam on sub cooled liquid jets. International Journal of Heat and Mass Transfer, 32(4): 639-654.

Dombrowski, N. and Munday, G. (1967) Biochemical and Biological Engineering Science, London: Academic Press.

Ford, J.D. and Lekic, A. (1971) Rate of growth of drops during condensation, International Journal of Heat and Mass Transfer, 16: 61-64.

Hinze, J.O. (1955) Fundamentals of the hydrodynamic mechanism of splitting in dispersion processes. American Institute of Chemical Engineers Journal, 1(3): 289-295.

Lee, S.Y. and Tankin, R.S. (1984) Study of liquid spray (water) in a condensable environment (steam). International Journal of Heat and Mass Transfer, 27(3): 363-374.

Mayinger, F. (1982) Strömung und Wärmeübergang in Flüssigkeitsgemischen. Berlin: Springer Verlag.

Mayinger, F. and Chavez, A. (1992) Measurement of direct-contact condensation of pure saturated vapor on an injection spray by applying pulsed laser holography. International Journal of Heat and Mass Transfer, 35(3): 691-702.

Mills, A.F., Kim, S., Leininger, T., Ofer, S. and Pessran A. (1982) Heat and Mass Transport in Turbulent Liquid Jets. International Journal of Heat and Mass Transfer, 25(6): 889-897.

Mochalova, N.S., Kholpanov, L.P. and Malyusov, V.A. (1988) Heat transfer in vapor condensation on laminar and turbulent liquid jets taking account of the inlet section and variability of the flow rate over the jet cross section. Institute of New Chemical Problems, Academy of Sciences of USSR, Moscow, 54(5): 732-735.

Nosoko, T., Miyara, A. and Nagata, T. (2002) Characteristics of falling film flow on completely wetted horizontal tubes and the associated gas absorption. International Journal of Heat and Mass Transfer, 45: 2729-2738.

Rao, V.D. and Sarma, P.K. (1985) Direct contact heat transfer in spherical geometry associated with phase transformation - a closed-form solution. International Journal of Heat and Mass Transfer, 28(10): 1956-1958. 
Steinberger, R.L. and Treybal, R.E. (1960) Mass transfer from a solid soluble sphere to a flowing liquid stream. American Institute of Chemical Engineers Journal, 6: $227-232$.

Sundararajan, T. and Ayyaswamy, P.S. (1987) Condensation on a moving drop: Effect of time dependent drop velocity. Proceedings of the $8^{\text {th }}$ National Conference on Heat and Mass Transfer, Visakhapatnam, India, pp. 453-459.

Takahashi, M., Arun Kumar, N., Kitagawa, S.I. and Murakoso, H. (2001) Heat Transfer in direct contact condensation of steam to subcooled water spray. International Journal of Heat and Mass Transfer, 123: 703-710.

\section{NOMENCLATURE}

A total surface area for heat transfer, $\mathrm{m}^{2}$

$A_{0} \quad$ cross sectional area of nozzle orifice, $\mathrm{m}^{2}$

$B$ parameter defined in Eq. $16 \mathrm{~b}$

$C$ parameter defined in Eq. 16a

$C_{A} \quad$ concentration of oxygen, $\left(=\rho_{L} X\right) \mathrm{kg} / \mathrm{m}^{3}$

$C_{P} \quad$ specific heat, $\mathrm{J} / \mathrm{kg} \mathrm{K}$

$d \quad$ droplet diameter, $\mathrm{m}$

$D$ diameter of the spray nozzle or jet, $m$

$D_{L} \quad$ diffusion coefficient or diffusivity of oxygen in water, $\mathrm{m}^{2} / \mathrm{s}$

$E \quad$ parameter defined in Eq. 9

$f_{1} f_{2} f_{3}$ parameters defined in Eq. $16 \mathrm{a}$

$F N$ flow number, $\mathrm{m}^{3} /\left[\mathrm{s}\left(\mathrm{N} / \mathrm{m}^{2}\right)^{1 / 2}\right]$

$\mathrm{Fr} \quad$ Froude number

$g \quad$ local acceleration of gravity, $\mathrm{m} / \mathrm{s}^{2}$

$G r_{d} \quad$ Grashof number, $\left[g d^{3}\left(\rho_{L}-\rho_{V}\right) / \rho_{L}\right]\left(\rho_{L} / \mu_{L}\right)^{2}$

$h \quad$ heat transfer coefficient, $\mathrm{W} / \mathrm{m}^{2} \mathrm{~K}$

$H_{f g} \quad$ latent heat of condensation, $\mathrm{J} / \mathrm{kg}$

$J a \quad$ Jacob number of liquid at inlet, $C_{P L}\left(T_{S}-T_{i}\right) / H_{f g}$

$k_{L} \quad$ mass transfer coefficient, $\mathrm{m} / \mathrm{s}$

$L \quad$ length, $\mathrm{m}$

$L_{B} \quad$ sheet break-up length, $\mathrm{m}$

$L_{h b} \quad$ hydraulic break-up length of the jet, $\mathrm{m}$

$m$ mass flow rate of water, $\mathrm{kg} / \mathrm{s}$

$m_{C} \quad$ mass flow rate of condensate, $\mathrm{kg} / \mathrm{s}$

$P_{D} \quad$ de-aerator pressure, $\mathrm{N} / \mathrm{m}^{2}$

$\Delta P$ pressure drop across the nozzle, $\mathrm{N} / \mathrm{m}^{2}$

Pr Prandtl number of liquid jet in stage $2, v_{L} / \alpha_{L}$

$q \quad$ parameter defined in Eq. 10

$Q \quad$ heat transfer, W

$r \quad$ time dependent radius of the droplet, $\mathrm{m}$

$r_{0} \quad$ radius of the droplet at time zero, $\mathrm{m}$ 
$r^{+} \quad$ dimensionless variable radius of the droplet, $r / r_{0}$

$r_{c o n}^{+} \quad$ dimensionless radius of the droplet during condensation

$R_{I} \quad$ inner radius of sheet, $R_{O}-\delta_{s}, \mathrm{~m}$

$R_{O} \quad$ outer radius of sheet, $S \times \sin 30, \mathrm{~m}$

$\operatorname{Re}_{d} \quad$ droplet Reynolds number, $d V / v_{V}$

$\operatorname{Re}_{J} \quad$ Reynolds number of liquid jet in stage 2 for mass transfer, $\Gamma / v_{L}$

$\operatorname{Re}_{H} \quad$ Reynolds number of liquid jet in stage 2 for heat transfer, $V_{2} D_{J} / 2 v_{L}$

Sc Schmidt number, $v_{L} / D_{L}$

$S \quad$ slant height, $\mathrm{m}$

$S h_{0} \quad$ initial Sherwood number

$S h_{d} \quad$ droplet Sherwood number, $k_{L, d} d / D_{L}$

$S h_{J} \quad$ Sherwood number of the liquid jet, $k_{L, J} \delta / D_{L}$

St Stanton number, $h_{2 T} / \rho_{L} V_{2} C_{P L 2}$

$t$ residence time, $\mathrm{s}$

$T$ temperature, $\mathrm{K}$

$T_{A V} \quad$ average temperature, $\left(T_{O}+T_{i}\right) / 2, \mathrm{~K}$

$\mathrm{U} \quad$ overall heat transfer coefficient, $\mathrm{W} / \mathrm{m}^{2} \mathrm{~K}$

$v \quad$ volume of liquid, $\mathrm{m}^{3}$

$v_{A}$ molecular volume of oxygen, $\mathrm{m}^{3} / \mathrm{kg}-\mathrm{mol}$

$V \quad$ Velocity of liquid, $\mathrm{m} / \mathrm{s}$

We Weber number of liquid, $\rho_{L} V^{2} D / 2 \sigma$

$X \quad$ mass fraction of $O_{2}$ in water, ppb

\section{Greek symbols}

$\alpha \quad$ thermal diffusivity, $\mathrm{m}^{2} / \mathrm{s}$

$\beta \quad$ coefficient defined in Eq. 10

$\Gamma \quad$ volumetric flow rate per jet perimeter, $\mathrm{m}^{2} / \mathrm{s}$

$\tau^{+} \quad$ dimensionless time, $4 \alpha t / d_{1}^{2}$

$\delta \quad$ Nusselt film thickness $\left(=\left(3 v_{L} \Gamma / g\right)^{1 / 3}\right), \mathrm{m}$

$\delta_{s} \quad$ sheet thickness, $\mathrm{m}$

$v \quad$ kinematic viscosity, $\mathrm{m}^{2} / \mathrm{s}$

$\mu \quad$ viscosity, $\mathrm{kg} / \mathrm{m} \mathrm{s}$

$\rho$ density, $\mathrm{kg} / \mathrm{m}^{3}$

$\sigma \quad$ surface tension, $\left[60.3-0.166\left(T_{i}-273.15\right)\right] 10^{-3}, \mathrm{~N} / \mathrm{m}$

\section{Subscripts}

A oxygen or non-condensable gas

$A V$ average

$C$ condensate 


$\begin{array}{ll}\text { con } & \text { condensation } \\ E & \text { energy balance } \\ \text { EXP } & \text { experiment } \\ d & \text { droplet } \\ H & \text { heat transfer } \\ i & \text { inlet } \\ J & \text { jet } \\ L & \text { liquid } \\ N & \text { nozzle } \\ o & \text { outlet } \\ \text { Reg } & \text { regression equation } \\ S & \text { sheet } \\ S & \text { saturation } \\ t & \text { tray } \\ T & \text { theoretical } \\ V & \text { water vapour } \\ 0 & \text { initial } \\ 1 & \text { first stage } \\ 2 & \text { second stage }\end{array}$

